\title{
TIPOS E INTENSIDADE DE DANOS MECÂNICOS EM BANANAS 'PRATA-ANÃ' AO LONGO DA CADEIA DE COMERCIALIZAÇÃO'
}

\author{
VICTOR MARTINS MAIA², LUIZ CARLOS CHAMHUM SALOMÃO ${ }^{3}$, DALMO LOPES SIQUEIRA³, ROLF PUSCHMANN ${ }^{4}$, \\ VIRGÍLIO JAMIR GONÇALVES MOTAFILHO ${ }^{5}$, PAULO ROBERTO CECON ${ }^{6}$
}

RESUMO - Atualmente, a maior parte da produção brasileira de banana é destinada ao mercado interno e, geralmente, é colhida, manuseada e transportada de forma deficiente e inadequada, contribuindo para perdas substanciais na fase pós-colheita. Objetivouse identificar os tipos e a intensidade de danos mecânicos após a colheita da banana 'Prata-Anã', produzida no Município de Verdelândia (MG) e embalada em caixas de papelão, madeira e plástico. Foram amostradas quatro caixas de banana 'Prata-Anã' em cada etapa da cadeia de comercialização, a saber: antes da colheita, após a primeira lavagem e pré-seleção ( $1^{\mathrm{a}}$ piscina da casa de embalagem), após embalagem, após transporte e após distribuição ao mercado varejista em Montes Claros (MG), onde os frutos permaneceram em exposição para vendas por 8 horas. A porcentagem de frutos, área da casca e porcentagem da área da casca danificados aumentou ao longo da cadeia de comercialização. $\mathrm{O}$ uso da caixa de papelão proporcionou redução na incidência e intensidade de dano mecânico em relação aos demais tipos de embalagem. Houve alta incidência do dano por abrasão em todas as etapas da cadeia de comercialização. O dano por compressão apresentou grande importância relativa no varejo.

Termos para indexação: Musa spp., perdas, pós-colheita.

\section{TYPES AND INTENSITY OF MECHANICAL DAMAGES ON 'PRATA ANÃ' BANANAS ALONG THE COMMERCIALIZATION CHAIN}

\begin{abstract}
Currently, most of the Brazilian production of banana is destined for domestic market and, generally, it is harvested, handled and carried in a deficient and inadequate form, contributing to substantial post harvest losses. This work had the objective of identifying the types and the intensity of mechanical damages after the harvest of 'Prata Anã' banana grown in Verdelândia, MG and put in cardboard, wood and plastic boxes. So, four boxes of banana were evaluated in each stage of the commercialization chain: before harvest, after the first washing and pre-selection ( $1^{\text {st }}$ swimming pool of the packing house), after packing, after transport and distribution to the retail market in Montes Claros, MG, where the fruits remained in exposition for sale during 8 hours. The percentage of fruits, skin area and percentage of the damaged skin area increased along of the commercialization chain. The use of the cardboard box provided reduction in the incidence and intensity of mechanical damage in relation to the other types of packing. There was high incidence of the damage caused by abrasion in all the stages of the commercialization chain. The damage by compression presented great relative importance in the retail.
\end{abstract}

Index terms: Musa spp., losses, post harvest.

\section{INTRODUÇÃO}

Atualmente, a maior parte da produção brasileira de bananas é destinada para o mercado interno e, geralmente, é colhida, manuseada e transportada de forma deficiente e inadequada, contribuindo para perdas substanciais na fase póscolheita (Alves, 1997), que são de grande importância do ponto de vista econômico e nutricional (Chitarra \& Chitarra, 1990).

As perdas ocorrem em todas as etapas entre a colheita e a comercialização, e seu efeito é cumulativo. Para bananas, as estimativas de perdas situam-se entre 20 e $80 \%$ (Coursey, 1983; Codevasf, 1989; Chitarra \& Chitarra, 1990; Ferris et al., 1995; Abanorte, 2005a). Essas estimativas de perdas, em alguns casos, são controvertidas, em parte, por carência de dados precisos, devido às muitas etapas entre a colheita e o consumo, e porque as perdas variam significativamente em função de safra, variedade, doenças, clima, colheita, processamento, manuseio e comercialização (Chitarra \& Chitarra, 1990).

A fase de transporte na lavoura é, talvez, a mais importante para a manutenção da boa aparência do produto, pois a maioria das pequenas batidas, pressões e abrasões ocorrem durante o transporte e o empilhamento dos cachos (Lichtemberg, 1999), causando manchas escuras que só se tornam visíveis na casca após a maturação (Dadzie \& Orchard, 1997; Lichtemberg, 1999). Segundo Robinson (1996), essa fase de transporte no campo é crítica porque pode determinar a quantidade de danos que o fruto embalado vai sofrer. A melhor forma de reduzir os danos nesta fase é o transporte por cabo aéreo (Lichtemberg,

${ }^{1}$ (Trabalho 128-07). Recebido em: 16-05-2007. Aceito para publicação em: 22-11-2007.

${ }^{2}$ Engenheiro Agrônomo, Dsc., Professor de Educação Superior, Universidade Estadual de Montes Claros - victor.maia@unimontes.br - Bolsista da Fapemig. Rua Reinaldo Viana 2630, 39440-000, Janaúba - MG.

${ }^{3}$ Professor Adjunto, DFT - UFV, 39570-000, Viçosa - MG - 1salomao@ufv.br - Bolsista do CNPq.

${ }^{4}$ Professor Titular, DBV - UFV, 39570-000, Viçosa - MG - rolf@ufv.br

${ }^{5}$ Engenheiro Agrônomo, Mestrando em Produção Vegetal no Semi-Árido da Unimontes - virgiliojamir@yahoo.com.br

${ }^{6}$ Professor Adjunto, DPI - UFV, 39570-000, Viçosa - MG - cecon@ufv.br 
1999), que leva a um manuseio mínimo dos frutos e uma menor abrasão entre eles, já que os cachos não se tocam nem são jogados ao chão (Robinson, 1996).

No momento da embalagem, os frutos também sofrem danos consideráveis que só se apresentam após a maturação (Dadzie \& Orchard, 1997; Lichtemberg, 1999). Os frutos com danos graves, provindos do manejo no campo e no transporte, são eliminados no momento da embalagem, enquanto os danificados na embalagem vão para as câmaras de climatização e para o mercado consumidor. Nessa fase, os maiores problemas ocorrem em função da utilização de embalagens inadequadas e, principalmente, em razão do excesso de cargas nelas acondicionadas, onde caixas dimensionadas para conter $20 \mathrm{~kg}$ são carregadas com mais de $28 \mathrm{~kg}$ de fruta (Lichtemberg, 1999). Tais abusos visam, não apenas a reduzir os custos de embalagem, mas também a compensar perdas posteriores para o atravessador (Lizada, 1994). Assim, a fruta é comprimida e ultrapassa a altura das caixas, e as conseqüências são frutos rachados, raspados, amassados e elevadas porcentagens de perdas (Lichtemberg, 1999).

Outra fase crítica é a de transporte para o mercado varejista, onde o meio mais utilizado é o rodoviário; fato agravado pela má conservação das estradas principais e vicinais das regiões produtoras (Alves, 1997), pelo transporte em horários cuja temperatura é elevada (Lichtemberg, 1999) e pelas grandes distâncias entre as regiões produtoras e o mercado consumidor (Robinson, 1996). Isso compromete seriamente a qualidade final do produto onde os danos causados por abrasão (Lichtemberg, 1999) e por vibração são bastante comuns (Dadzie \& Orchard, 1997).

Na etapa de climatização, ocorrem danos ligados principalmente às altas temperaturas a que os frutos são submetidos (frutos "cozidos" com vida de prateleira reduzida e intensificação do despencamento) e a carga e descarga do caminhão (Lichtemberg, 1999). Durante as cargas e descargas das caixas de banana no mercado atacadista, os frutos são literalmente atirados na troca de embalagens, ocorrendo diversos tipos de danos tanto nos verdes quanto nos maduros. No mercado varejista, as pencas são amontoadas nas gôndolas, resultando em ferimentos, despencamento, esmagamento e podridões (Lichtemberg, 1999).

Percebe-se, então, que o dano mecânico é uma das principais causas de perdas pós-colheita em banana (Dadzie \& Orchard, 1997; Ferris et al., 1995; Lladó \& Dominguez, 1998), resultando na redução da vida pós-colheita e na não-aceitação do fruto.

Embora não seja possível eliminar totalmente as perdas, estas podem ser minimizadas com o entendimento da natureza do produto, dos processos de colheita e comercialização, e da utilização dos produtos descartados em programas sociais. Para isso, existe um custo associado, que é consideravelmente menor que o custo necessário para produzir mais. Esse conhecimento é bastante usual nos países desenvolvidos de forma a reduzir as perdas em geral de seus produtos e pouco comum nos países subdesenvolvidos e em desenvolvimento (Chitarra \& Chitarra, 1990).
Portanto, para que as perdas pós-colheita sejam sensivelmente reduzidas, tornam-se necessários a identificação quantitativa e o local exato das perdas em todo o sistema de produção e comercialização. A partir desses dados, podem-se melhorar os processos para aumentar a disponibilidade de alimentos, fornecer bases para tomada de decisão por parte de agências nacionais e internacionais sobre alocação de recursos, além de atender aos consumidores que cada vez mais desejam frutos com alta qualidade e preços acessíveis e aos produtores que vão obter um produto com melhor preço de venda.

O objetivo deste trabalho foi identificar os tipos e a intensidade de dano mecânico em diversas etapas do processo entre a colheita e a comercialização no mercado varejista da banana 'Prata-Anã' produzida no município de Verdelândia-MG, e embalada em caixas de papelão, madeira e plástico.

\section{MATERIAL E MÉTODOS}

Para estimar a área superficial dos frutos (área da casca), inicialmente, ajustou-se uma equação baseada nos parâmetros físicos do fruto e suas combinações. Para isso, foram utilizadas 40 bananas (Musa spp.) 'Prata-Ana' (AAB), obtidas em pomar comercial da Fazenda Cachoeira do Salto, de propriedade da Agropecuária Veloso Maia, localizada no Município de Verdelândia-MG $\left(15^{\circ} 24^{\prime} \mathrm{S}, 43^{\circ} 43^{\prime} \mathrm{W}, 480 \mathrm{~m}\right.$ de altitude, clima do tipo Aw, segundo a classificação de Köppen) e transportadas até a Universidade Federal de Viçosa.

Os cachos foram colhidos em novembro de 2003, quando o fruto central da segunda penca atingiu o diâmetro de $36 \pm 2$ $\mathrm{mm}$. Uma vez colhidos, os cachos foram lavados com água na casa de embalagem da propriedade, sendo, então, despencados. A segunda, a terceira e a quarta pencas de cada cacho foram identificadas, envolvidas com plástico-bolha e acondicionadas em caixas de papelão. As caixas foram transportadas para o Laboratório de Pós-Colheita do Departamento de Fitotecnia da Universidade Federal de Viçosa onde, cerca de 24 horas após a colheita, os frutos foram individualizados por um corte rente à almofada floral e lavados em solução de detergente a $0,2 \%$, por cinco minutos.

Após esse processo, os frutos foram acondicionados em caixas plásticas forradas com papel picado e mantidos em condição ambiente (médias de $25,4 \pm 1,9^{\circ} \mathrm{C}$ e $82 \pm 9,1 \%$ de umidade relativa do ar) até atingir o índice de cor da casca 6 (Dadzie \& Orchard, 1997), ou seja, fruto todo amarelo. Nesse momento, foram avaliados a massa fresca, comprimento total e comercial (comprimento da polpa), diâmetro e circunferência (Dadzie \& Orchard, 1997; Ministério da Integração Nacional, 2000) dos frutos, bem como a área da casca dos mesmos com o auxílio de um medidor de área foliar portátil ADC Bioscientific Ltd (England) Area Meter AM 100.

A partir desses dados, foram estimadas correlações relacionando uma ou mais características medidas, bem como as combinações entre elas, e a área da casca obtida, determinandose uma equação com o auxílio do software SAEG 5.0.

Para a determinação dos tipos e da intensidade de danos que ocorrem ao longo da cadeia de comercialização, os frutos 
foram amostrados aleatoriamente nas várias etapas dessa cadeia, desde a colheita até a distribuição ao varejista. A amostragem inicial ocorreu em pomar comercial da Fazenda Cachoeira do Salto, de propriedade da Agropecuária Veloso Maia, localizada no Município de Verdelândia (MG), e a final, no Sacolão Ceamoc, localizado em Montes Claros (MG), acerca de 250 km de distância. Os tipos de danos identificados foram corte, abrasão, impacto e compressão.

Na propriedade escolhida, utilizam-se as seguintes formas de colheita, embalagem e transporte: uso de espuma nas costas do colhedor do cacho, transporte na lavoura por cabo aéreo, casa de embalagem que seleciona, classifica e lava as pencas, uso de embalagens de papelão, com capacidade de 18,7 a 19,7 kg e medidas de 49,1 x 38,1 x 26,4 cm; de plástico com capacidade de 13,0 a $13,8 \mathrm{~kg}$ e medidas de $60 \times 40 \times 23 \mathrm{~cm}$; de madeira, com capacidade de 22 a $23 \mathrm{~kg}$ e medidas de 50 × $35 \times 28 \mathrm{~cm}$ (Abanorte, 2005 b) e transporte em caminhão aberto. Não foram feitas intervenções nos procedimentos-padrão adotados na propriedade.

Foram amostrados quatro cachos ou caixas, de cada tipo, em cada etapa da cadeia de comercialização, a saber: antes da colheita, após a primeira lavagem e pré-seleção ( $1^{\mathrm{a}}$ piscina da casa de embalagem), após embalagem, após transporte e após distribuição ao mercado varejista em Montes Claros (MG), onde os frutos permaneceram em exposição para vendas por 8 horas.

Subamostras de trinta frutos de cada caixa ou cacho foram retiradas aleatoriamente e transferidas para bandejas plásticas revestidas com fitilhos de papel, evitando novos danos, sendo mantidas em local próximo à amostragem e analisados ao atingir o estádio de coloração 6 (Dadzie \& Orchard, 1997). Os frutos obtidos em cada etapa foram mantidos em condição ambiente e analisados quanto à porcentagem de frutos danificados, a porcentagem dos tipos de danos mecânicos sofridos em relação ao total desses frutos, à área da casca danificada e sua porcentagem.

A porcentagem dos tipos de danos mecânicos foi determinada em relação ao total de frutos danificados, ou seja, a razão entre o número de frutos com determinado tipo de dano mecânico e o número total de frutos danificados, multiplicado por 100. A área da casca danificada foi obtida pela técnica das quadrículas, utilizando-se de um papel milimetrado. Esse atributo foi determinado recortando da casca do fruto as regiões danificadas com auxílio de um bisturi e desenhando essa secção em papel milimetrado, o que permitiu a sua quantificação. A partir desse dado e da área da casca do fruto em função da massa, obteve-se a porcentagem da área do fruto danificada em relação à área total da casca. Utilizou-se estatística descritiva para análise dos dados.

\section{RESULTADOS E DISCUSSÃO}

Entre todos os atributos avaliados e suas combinações, a que apresentou maior correlação com a área da casca de bananas 'Prata-Anã' foi a massa da matéria fresca do fruto. Esse resultado é semelhante ao obtido por Ferris (1991), citado por Ferris et al. (1995), que observou alta correlação entre a área da casca e a massa de bananas. A partir dessa característica, foi ajustada a seguinte equação:

$$
\begin{aligned}
& \mathrm{AC}=33,30+0,904834 \mathrm{P} \\
& \mathrm{AC}=\text { área da casca }\left(\mathrm{cm}^{2}\right) \\
& \mathrm{P}=\text { massa do fruto }(\mathrm{g}) .
\end{aligned}
$$

$$
r^{2}=0,91 \text { onde: }
$$

A partir da equação ajustada, foi possível determinar a área da casca em função do peso do fruto, e a porcentagem do fruto danificado mecanicamente, a partir da área da casca injuriada obtida com o auxílio de um papel milimetrado.

Em todos os pontos de amostragem de banana 'PrataAnã', ao longo da cadeia de comercialização, foi observada a presença de frutos com dano mecânico (Figura 1). Além disso, ocorreu um aumento cumulativo de frutos danificados (\%), área $\left(\mathrm{cm}^{2}\right)$ e porcentagem da casca danificada entre a colheita e o varejo, independentemente da embalagem utilizada (Figuras 1;2 e 3$)$.

O uso da embalagem de papelão proporcionou menor porcentagem de frutos danificados, área e porcentagem da casca danificada em relação às embalagens de plástico e madeira, as quais apresentaram valores próximos da porcentagem de frutos danificados nas amostragens realizadas após o transporte e o varejo (Figuras 1;2 e 3).

Considerando a área da casca da banana danificada $\left(\mathrm{cm}^{2}\right)$ e a porcentagem da área da casca, percebe-se que o uso da embalagem de madeira provocou os maiores danos em relação à caixa de plástico, sendo que, a partir da amostragem realizada após a embalagem, esses valores foram bastante elevados. Entretanto, os frutos amostrados no varejo-procedentes da caixa de plástico apresentaram esses valores mais elevados e bem próximos daqueles amostrados no varejo procedentes da caixa de madeira (Figuras 2 e 3 ).

Em relação à ocorrência de cada tipo de dano mecânico em cada ponto de amostragem, ao longo da cadeia de comercialização, foi observado que, após a embalagem dos frutos, com exceção daqueles coletados após a embalagem em caixa de papelão e madeira, ocorreu a presença dos quatro tipos de dano mecânico, ou seja, corte, abrasão, impacto e compressão (Figura 4).

O dano mecânico por abrasão apresentou valores elevados de ocorrência em todos os pontos de amostragem, sendo superior aos demais após a $1^{\mathrm{a}}$ piscina da casa de embalagem, após a embalagem, após o transporte e após o varejo nos frutos procedentes da caixa de plástico. O dano por corte, por sua vez, não foi observado apenas nos frutos coletados no cacho, mostrando altos valores de ocorrência em todas as demais etapas amostradas ao longo da cadeia de comercialização. O dano por impacto apresentou valores elevados de incidência nos frutos obtidos nos primeiros pontos de amostragem da cadeia de comercialização, observando-se uma redução de sua importância relativa a partir da embalagem dos frutos.

De forma contrária ao dano mecânico por corte, o dano por compressão, não foi observado nos frutos obtidos nas amostragens iniciais, isto é, frutos amostrados no cacho, após a $1^{\text {a }}$ piscina da casa de embalagem e após a embalagem em caixa de 
papelão, mas apresentou aumento da sua importância relativa, ao longo da cadeia de comercialização, atingindo, nos frutos amostrados no varejo, valores próximos e/ou superiores ao dano por abrasão (Figura 4).

A partir dos dados observados e pelo acompanhamento dos processos de comercialização de bananas, algumas medidas podem ser sugeridas para reduzir a porcentagem de frutos danificados, a área da casca $\left(\mathrm{cm}^{2}\right)$ danificada, a porcentagem da área da casca danificada e a incidência dos quatro tipos de dano mecânico em cada etapa da cadeia de comercialização. São elas: promover treinamento do pessoal envolvido em toda a cadeia de comercialização de bananas para diminuir a porcentagem de frutos danificados e a incidência dos quatro tipos de dano mecânico; utilizar, nas bordas das piscinas das casas de embalagem, material emborrachado de forma a evitar o dano por abrasão; evitar o excesso de carga e carga alta nas caixas para reduzir a incidência dos danos por abrasão e compressão; preterir o uso das caixas de madeira e plásticas, que promovem altos valores de dano por abrasão e compressão, bem como área da casca danificada; melhorar as embalagens de papelão, utilizando material menos áspero, reduzindo sua capacidade e aumentando a resistência ao empilhamento para diminuir a incidência dos danos por abrasão e compressão; e alterar a maneira de comercialização de bananas, evitando-se o uso de pencas e dando preferência pelo uso do buquê com poucos frutos ou frutos individualizados.

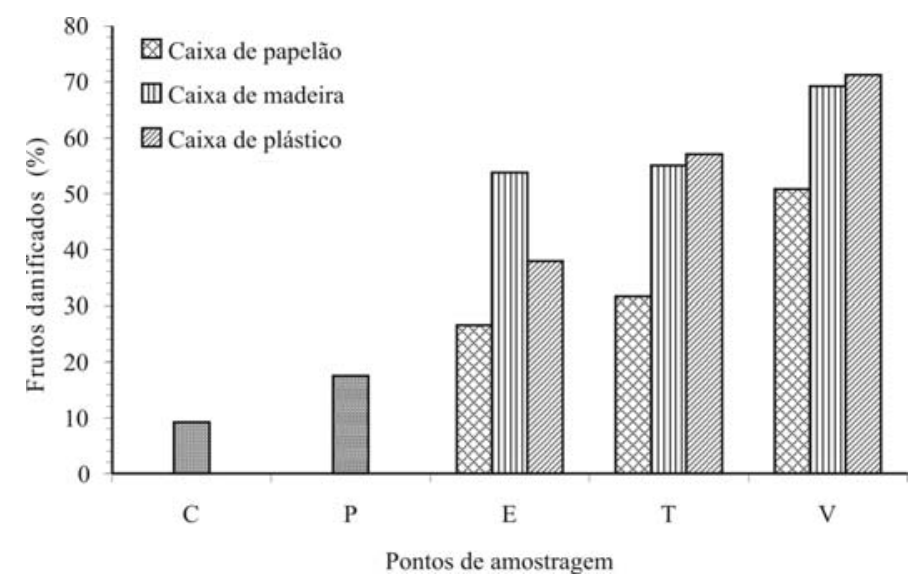

FIGURA 1 - Porcentagem de bananas 'Prata-Anã' com sintomas de dano mecânico, ao longo cadeia de comercialização. $\mathrm{C}=$ frutos coletados no cacho; $\mathrm{P}$ $=$ frutos coletados após a $1^{\mathrm{a}}$ piscina da casa de embalagem; $\mathrm{E}=$ frutos coletados após a embalagem; $\mathrm{T}=$ frutos coletados após o transporte, e $\mathrm{V}=$ frutos coletados após o varejo.

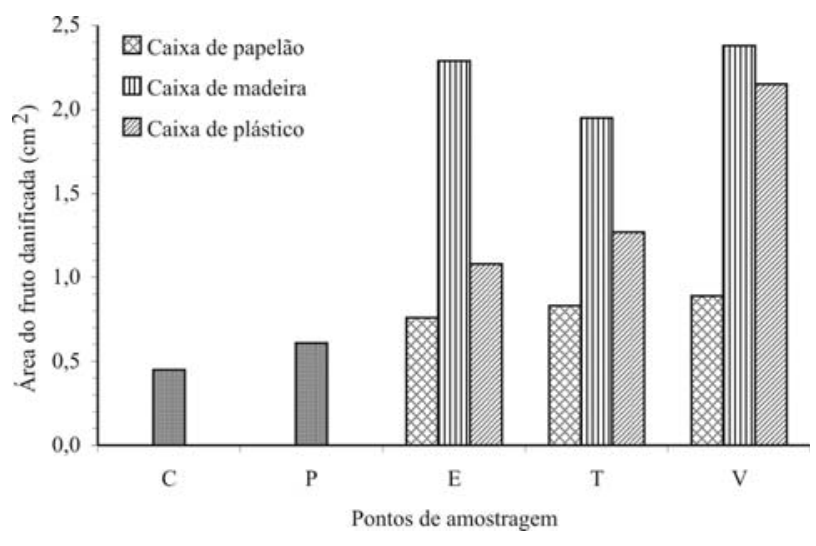

FIGURA 2 - Área da casca $\left(\mathrm{cm}^{2}\right)$ de bananas 'Prata-Anã' com sintomas de dano mecânico, ao longo da cadeia de comercialização. $\mathrm{C}=$ frutos coletados no cacho; $\mathrm{P}=$ frutos coletados após a $1^{\mathrm{a}}$ piscina da casa de embalagem; $\mathrm{E}=$ frutos coletados após a embalagem; $\mathrm{T}=$ frutos coletados após o transporte , e $\mathrm{V}=$ frutos coletados após o varejo.

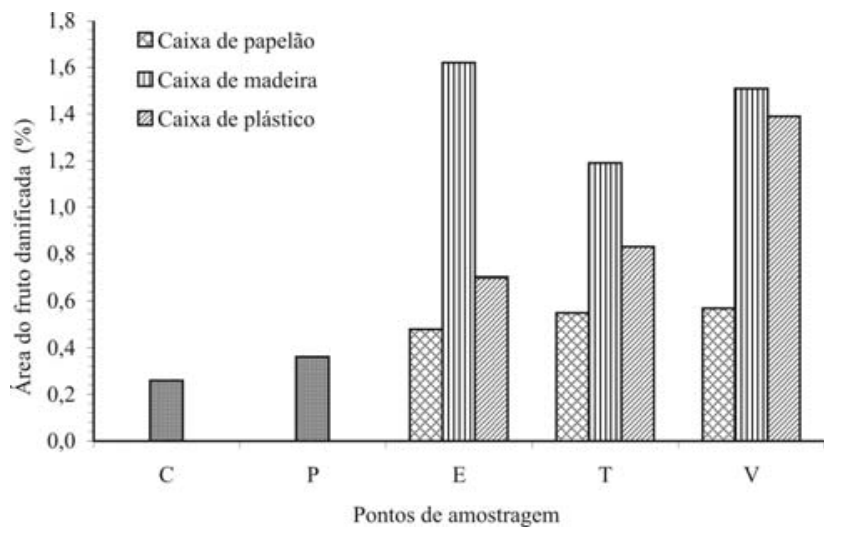

FIGURA 3 - Porcentagem da área da casca de bananas 'Prata-Anã'com sintomas de dano mecânico, ao longo da cadeia de comercialização; $\mathrm{C}=$ frutos coletados no cacho; $\mathrm{P}=$ frutos coletados após a $1^{\mathrm{a}}$ piscina da casa de embalagem; $\mathrm{E}=$ frutos coletados após a embalagem; $\mathrm{T}$ = frutos coletados após o transporte, $\mathrm{e} \mathrm{V}=$ frutos coletados após o varejo. 


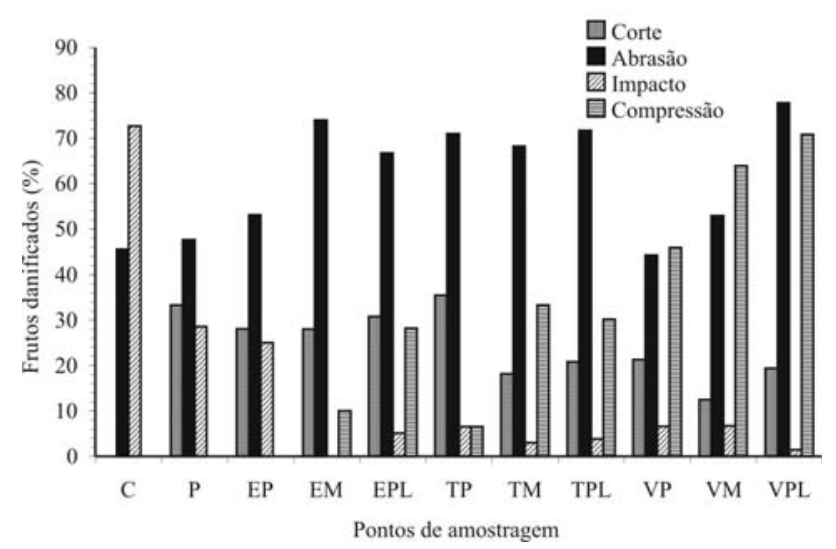

FIGURA 4 - Porcentagem de bananas 'Prata-Anã' danificadas por corte, abrasão, impacto e compressão em relação ao total de frutos danificados, ao longo da cadeia de comercialização. $\mathrm{C}=$ frutos coletados no cacho; $\mathrm{P}=$ frutos coletados após a $1^{\mathrm{a}}$ piscina da casa de embalagem;EP = frutos coletados após a embalagem com caixa de papelão; $\mathrm{EM}=$ frutos coletados após a embalagem com caixa de madeira; $\mathrm{EPL}=$ frutos coletados após a embalagem com caixa de plástico; $\mathrm{TP}=$ frutos coletados após o transporte em caixa de papelão; TM = frutos coletados após o transporte em caixa de madeira; TPL = frutos coletados após o transporte em caixa de plástico; $\mathrm{VP}=$ frutos coletados após o varejo com procedência de caixa de papelão; VM = frutos coletados após o varejo com procedência de caixa de madeira, e VPL = frutos coletados após o varejo com procedência de caixa de plástico.

\section{CONCLUSÕES}

1- Existe uma alta correlação entre a massa e a área da casca da banana 'Prata-Anã'.

2-A porcentagem de frutos danificados, a área da casca danificada e a porcentagem da área da casca danificada aumentaram ao longo da cadeia de comercialização de bananas 'Prata-Anã'.

4-O uso da caixa de papelão reduziu a incidência e a intensidade de dano mecânico em bananas 'Prata-Anã' em relação aos demais tipos de embalagem.

5-O dano por abrasão em bananas 'Prata-Anã' apresentou altos valores de incidência em todas as etapas da cadeia de comercialização.

6-O dano por compressão em bananas 'Prata-Anã' apresentou grande importância relativa no varejo.

\section{AGRADECIMENTOS}

Ao Conselho Nacional de Desenvolvimento Científico e Tecnológico (CNPq), a Fundação de Amparo à Pesquisa do Estado de Minas Gerais e à Agropecuária Veloso Maia.

\section{REFERÊNCIAS}

ABANORTE - Associação Central dos Fruticultores do Norte de Minas. Banana: índice de perda até o consumo final chega a 60\%. 2005. Disponível em: <http://www.abanorte.com.br/ n o t i c i a s/n a c i o n a $1 / \mathrm{d}$ o c b a n a n a / view? searchterm=Dimensões $20 \%$ embalagens $>$. Acesso em: 22 ago 2005 .
ABANORTE - Associação Central dos Fruticultores do Norte de Minas. Normas de empacotamento. 2005b. Disponível em: $<\mathrm{http}: /$ /www.abanorte.com.br> Acesso em: 22 ago 2005.

ALVES, E. J., (Org.). A cultura da banana: aspectos técnicos, socioeconômicos e agroindustriais. Brasília: Embrapa-SPI/Cruz das Almas: Embrapa-CNPMF, 1997. 585 p.

CHITARRA, M. I. F.; CHITARRA, A. B. Pós colheita de frutos e hortaliças: fisiologia e manuseio. Lavras: ESAL/ FAEPE, 1990. $320 \mathrm{p}$.

CODEVASF. Exportações de frutas brasileiras. Brasília: 1989. $352 \mathrm{p}$.

COURSEY, D. G. Post harvest losses in perishable foods of the developing world. New York: Plenum, 1983. v.16, p. 485-514.

DADZIE, B. K.; ORCHARD, J. E. Routine post-harvest screening of banana/plantain hybrids: criteria and methods. Inibap Technical Guidelines 2. Montpellier: International Network for the Improvement of Banana and Plantains, 1997. 63 p.

FERRIS, R .S. B.; WAINWRIGHT, H.; THOMPSON, A. K. The effects of morphology, maturity and cultivar on the ripening and susceptibility of plantains (AAB) to mechanical damage. Fruits, Paris, v. 50, n. 2, p. 101-107, 1995.

LICHTEMBERG, L. A. Colheita e pós-colheita de banana. Banana: produção, colheita e pós-colheita. Informe Agropecuário, Belo Horizonte, v.20, n. 196, p.73-90. 1999. 
LIZADA, M. C. C. Fruit handling systems in developing countries In: CHAMP, B. R.; HIGHLEY, E.; JOHNSON, G.I., (Eds.). Postharvest handling of tropical fruits. Camberra: Aciar Proceedings, 1994. p. 109-115.

LLADÓ, J. D. S.; DOMINGUEZ, A. M. The effects of peel abrasion on the postharvest physiology and commercial life of banana fruits. Acta Horticulturae, Wageningen, n. 490, p. 547-553, 1998.
MINISTÉRIO DA INTEGRAÇÃO NACIONAL. Frutiséries banana, 2000. Disponível em: <http://www.integracao.gov.br/ publicacoes.html>. Acesso em: 23 jun. 2001.

ROBINSON, J. C. Bananas and plantains. Cambridge: CAB Internacional, $1996.238 \mathrm{p}$. 